Original Research Paper

\title{
Evaluation of Effect of Clinical Nurse Mentors Assigned to Nursing Students upon Level of Satisfaction Regarding Clinical Teaching-Learning Process
}

\author{
Jayalakshmi, N., Shobha Naidu, Kevin Christian and Sanopant Joshi \\ Symbiosis College of Nursing (SCON), \\ Symbiosis International University, Pune, Maharashtra, India
}

Article history

Received: 21-05-2016

Revised: 26-09-2016

Accepted: 28-09-2016

Corresponding Author: Jayalakshmi, N.

Symbiosis College of Nursing (SCON), Symbiosis International University, Pune, Maharashtra, India E-mail: director@scon.edu.in

\begin{abstract}
Mentoring is an important teaching-learning process in undergraduate nursing Curricula. A Quasi experimental one group pretest and post test design was conducted on 30 students of 1st and 2nd Year B.Sc Nursing from Symbiosis College of Nursing, Pune to evaluate the effect of Clinical Nurse Mentors. Non-Probability Random Sampling was used to select the students. The study was undertaken over a month period. The students attempted the satisfaction scale tool before and after the exposure to Clinical Nurse Mentors. The analysis was done using percentage calculation for demographic data and non-parametric Chi square test for analyzing the data collected regarding satisfaction level. The statistical analysis revealed that majority of the respondents were females, 18-19 years of age. The student satisfaction level was calculated to be significantly high after the appointment of Clinical Nurse Mentors in following areas:
\end{abstract}

1. Duration of clinical supervision (Chi Square value 144, significant at level $\mathrm{p}=0.001$ )

2. Clarification of doubts of students in clinical setup (Chi Square value 172 , significant at level $\mathrm{p}=0.001$ )

3. Satisfaction level regarding self-confidence while performing Advanced and Basic clinical nursing procedures (Chi Square value 118 , significant at level $\mathrm{p}=0.001$ )

4. Opportunities to practice Basic and Advanced clinical procedures (Chi Square value 129.6, significant at level $\mathrm{p}=0.001$ )

5. Regularity of clinical teaching (Chi Square value 124, significant at level $\mathrm{p}=0.001$ )

6. Empathetic treatment from teacher in clinical setup (Chi Square value 92, significant at level $p=0.001$ )

7. Provision of individual attention for students (Chi Square value 29.87, significant at level $\mathrm{p}=0.001$ )

8. Ability to communicate the problems to the teacher (Chi Square value 84.9 , significant at level $\mathrm{p}=0.001$ )

9. Motivational level to perform better in clinical setup (Chi Square value 116 significant at level $\mathrm{p}=0.001$ )

The study confirmed the value of mentorship in Under Graduate (UG) Nursing Program and highlighted the importance of skill competence as a basis for professional role identity by Baccalaureate students. Thus appointment of Clinical Nurse Mentors for the purpose of clinical teaching learning process may be a good decision by Colleges of Nursing.

Keywords: Clinical Nurse Mentors, Under Graduate Nursing Students 


\section{Introduction}

'Mentoring' as a concept and practice, that is in reference to facilitating professional learning in healthcare, this has evolved consistently since the 1970s and was formally implemented in pre-registration nursing and midwifery education in the 1980s. In the Shorter Oxford English Dictionary (William et al., 2002), the term 'mentor' originates from the Greek classical story 'The Odyssey' in which King Odysseus called upon a trusted friend and named him Mentor to act as the guide and advisor to his young son Telemachus, when he left for another country to fight a war (Andrews and Chilton, 2010). The word mentor also relates to the Latin word 'men's' that is, pertaining to, or occurring in the mind (Simpson and Weiner, 1989). The term has gradually evolved to signify a designated person who dedicates some of his time to help individuals to learn during their developmental years, to progress towards and achieve maturity and establish their identity (Andrews and Roberts, 2003). It has been implemented as a formal role in nurse education to direct focus on enabling students to gain safe and effective clinical practice skills during practice placements. This section disentangles the concept of mentor from similar titles by exploring the differences and similarities between them.

Mentoring is a learning and developmental process that assists students' achievement of competencies, orientation to the clinical role and personal and professional accomplishment (Ehrich et al., 2002), the opportunity to reduce the theory-practice-gap (Chow and Suen, 2001). With the growing emphasis on expanding evidence-based practice in nursing, however, mentoring within the context of research is becoming increasingly important.

Review of Literature revealed that appointment of Clinical Nurse Mentors is a newer trend in Nursing Education, ensuring holistic nursing Education for the students.

A study conducted by Marilyn et al. (2004) indicates that presence of Nurse Mentors as teachers in clinical setup was highly appreciated by the students. His study showed that above all, a job that was regarded as permanent and perceived as a connection to Nursing education by the Nurse Mentors, caused them to be more receptive towards students learning process and significantly boosted the job satisfaction score, with a marginal increment for not having to work unpaid overtime (Gray and Smith, 2000).

\section{Statement of the Problem}

"Evaluation of effect of Clinical Nurse Mentors assigned to nursing students upon level of satisfaction regarding clinical teaching-learning process".

\section{Objectives:}

1. To assess the feasibility of appointing Clinical Nurse Mentors to nursing students.

2. To evaluate the effect of appointing Clinical Nurse Mentors for nursing students upon the satisfaction of nursing students regarding clinical teaching-learning process.

3. To evaluate the satisfaction level of the Clinical Nurse Mentors regarding this clinical teachinglearning process.

\section{Hypothesis:}

$\mathrm{H}_{1}$ : It is feasible to appoint Clinical Nurse Mentors for the nursing students for the purpose of effective teaching learning process.

$\mathrm{H}_{2}$ : The students will achieve significant increase in levels of satisfaction regarding clinical teachinglearning activity by Clinical Nurse Mentors

$\mathrm{H}_{3}$ : The Clinical Nurse Mentors will achieve significant increase in levels of satisfaction regarding their jobs after introducing Clinical Nurse Mentorship in their job descriptions.

\section{Methodology:}

- Research Approach: An evaluative approach was used for the present study.

- Study Design: Quasi experimental; one group pretest posttest design

- Sample Size: 30

- Sampling technique: Non-Probability Random Sampling was used

- Sampling Frame: 1st and 2nd year B.Sc Nursing students of Symbiosis College of Nursing, Pune city, the study was undertaken over a period of one month.

\section{Variables under Study:}

\section{Independent Variable:}

- Clinical Teaching by Clinical Nurse Mentors

\section{Variable:}

- The satisfaction level of nursing students regarding the clinical teaching learning process

- The satisfaction level of Clinical Nurse Mentors regarding their jobs after inclusion of clinical mentorship

\section{Socio-Demographic Variables}

In this study socio-demographic variables refer to the selected variables regarding the Clinical Nurse Mentors, like age, gender, educational background, religion, year of study. 


\section{Setting of the Study:}

The present study was conducted at Symbiosis College of Nursing, Pune.

\section{Population:}

- Target Population: Nursing students and Staff nurses working in various hospitals of Pune city.

- Accessible population: Nursing students of Symbiosis College of Nursing and Staff Nurses working in selected Hospitals of Pune city, Maharashtra.

\section{Criteria for Selection of Sample:}

Inclusion Criteria:

1. Students who are physically fit to be part of research study.

2. Staff nurses who have undergone degree programme in nursing.

3. Staff Nurses having at least 2 years of clinical experience.

4. Students and Staff Nurses who are willing to participate in the study.

\section{Exclusion Criteria:}

1. Students and Staff nurses having out of ordinary personal/academic stress.

2. Students undergoing P.B.B.Sc course.

3. Students who are recurrent absentees from the clinical field.

\section{Description of Tools:}

Tool was developed by the investigator after extensive review of literature. The Tool has two parts.

\section{For Students:}

A: Demographic data

B: Likert scale to measure satisfaction level regarding clinical teaching learning process.

\section{For Clinical Nurse Mentors:}

A: Demographic data

B: Likert scale to measure satisfaction level regarding job description

\section{Validity and Reliability of the Tool}

Tool was sent for content validity to five experts from the field of Nursing. Pilot study was conducted on five students of another institute to check the reliability of the tool. The reliability of tool was calculated by Split-half technique and was 0.78 which was reliable. These students were not included in the main study.

\section{Data Collection Procedure}

Pre-test satisfaction level of Student nurses was assessed before the appointment of Clinical Nurse Mentors with regard to duration of clinical supervision, clarification of doubts, level of confidence while performing clinical procedures, opportunities to practice Basic and Advanced nursing procedures, regularity of clinical teaching, empathetic treatment during clinical postings, provision of individual attention, communication of problems to Supervisor, scheduling of return demonstrations, motivation to perform better in clinical field, permanent appointment of Nurse Mentors.

Post-test satisfaction level of Student nurses was assessed after the appointment of Clinical Nurse Mentors using the same Questionnaire, at the same place, in regard to duration of clinical supervision, clarification of doubts, level of confidence while performing clinical procedures, opportunities to practice Basic and Advanced nursing procedures, regularity of clinical teaching, empathetic treatment during clinical postings, provision of individual attention, communication of problems to supervisor, scheduling of return demonstrations, motivation to perform better in clinical field, permanent appointment of Nurse Mentors.

\section{Results and Discussion}

As displayed in the Table 1, at Serial No. 1, there was a significant increase $(p=0.001)$ in the level of satisfaction of students regarding the clinical supervision provided during clinical posting. The interpretation to be drawn is that presence of Nurse Mentors significantly enhances the satisfaction level of the students regarding clinical teaching practices. Therefore, $\mathrm{H}_{2}$ is accepted, $\mathrm{H}_{0}$ is rejected.

As displayed in table, at Serial No. 2, there was a significant increase on scale $(p=0.001$ in the level of satisfaction of students regarding clarification of doubts regarding procedures performed in the wards. Nurse Mentors were better able to clarify the doubts as compared to Clinical Instructors. Therefore, $\mathrm{H}_{1}$ is accepted, $\mathrm{H}_{0}$ is rejected.

As displayed in table, at Serial No. 3, there was a significant increase on scale $(\mathrm{p}=0.001)$ in the level of satisfaction of students regarding the confidence while performing clinical procedures. Presence of Nursing Mentors increased the level of confidence of the students more as compared to Clinical Instructors. Therefore, $\mathrm{H}_{1}$ is accepted, $\mathrm{H}_{0}$ is rejected.

As displayed in, at Serial No.4, students claimed that they got significantly better opportunities to perform advanced and basic nursing procedures under the guidance of Nurse Mentors, as compared to Clinical Instructors. The value was significant at $\mathrm{p}=0.001$ scale. Therefore, $\mathrm{H}_{2}$ is accepted, $\mathrm{H}_{0}$ is rejected. 
Table 1. Satisfaction level of students in various areas of satisfaction

\begin{tabular}{lllll}
\hline & & $\begin{array}{l}\text { Satisfaction level } \\
\text { before appointing } \\
\text { clinical mentors }\end{array}$ & $\begin{array}{l}\text { Satisfaction level } \\
\text { after appointing } \\
\text { clinical mentors }\end{array}$ & Chi square \\
\hline 1 & Areas of Satisfaction & -36 & 36 & $144^{*}$ \\
2 & Duration of clinical supervision & -43 & 45 & $172^{*}$ \\
3 & Level of confidence while performing clinical procedures & -23 & 39 & $118.56^{*}$ \\
4 & Opportunities to practice basic and advanced nursing procedures & -32 & 40 & $129.6^{*}$ \\
5 & Regularity of clinical teaching & -31 & 35 & $124.45^{*}$ \\
6 & Empathetic treatment during clinical postings & -23 & 24 & $92.04^{*}$ \\
7 & Provision of Individual attention & 06 & 41 & $29.87^{*}$ \\
8 & Communication of problems to supervisor & -21 & 26 & $84.96^{*}$ \\
9 & Scheduling of return demonstrations & 30 & 35 & $0.71^{*}$ \\
10 & Motivation to perform better in clinical field & -27 & 47 & $116.51^{*}$ \\
11 & Permanent appointment of Nurse Mentors & - & 59 & - \\
\hline- & Significant at 0.05 level & &
\end{tabular}

11 Permanent appointment of Nurse Mentors

As displayed in table, at Serial No. 5, the level of satisfaction of students was significantly higher on scale $(\mathrm{p}=0.001)$ regarding regularity of clinical teaching taking place in clinical setup under the guidance of Nurse Mentors as compared to Clinical Instructors. Thus, it can be interpreted that Nurse Mentors ensure better scheduling and continuity of bed side nursing education. Therefore, $\mathrm{H}_{2}$ is accepted, $\mathrm{H}_{0}$ is rejected.

As displayed in table, at Serial No. 6, the level of satisfaction of students was significantly higher on scale $(p=0.001)$ regarding empathetic treatment given to them by Nurse Mentors as compared to Clinical Instructors. It can be interpreted that the longer the time spent with the students makes the Nurse Mentors more empathetic towards the students as compared to Clinical Instructors. Therefore, $\mathrm{H}_{2}$ accepted, $\mathrm{H}_{0}$ is rejected.

As displayed in table, at Serial No. 7, the level of satisfaction of students was significantly higher on scale $(p=0.001)$ regarding Individual attention given to each student in clinical setup under the guidance of Nurse Mentors, as compared to Clinical Instructors. Thus, it can be interpreted that Nurse Mentors pay better attention to individual students as compared to the Clinical Instructors. Therefore, $\mathrm{H}_{1}$ accepted, $\mathrm{H}_{0}$ is rejected.

As displayed in table, at Serial No. 8, the level of satisfaction of students was significantly higher on scale $(p=0.001)$ regarding ease of communicating problems related to teaching-learning in clinical setup under the guidance of Nurse Mentors, as compared to Clinical Instructors. Thus, it can be interpreted that Nurse Mentors are able to guide the students better in clinical set up as compared to the Clinical Instructors. Therefore, $\mathrm{H}_{1}$ accepted, $\mathrm{H}_{0}$ is rejected.

As displayed in table, at Serial No.9, the level of satisfaction of students was not significantly distinguishable on scale $(\mathrm{p}=0.001)$ regarding scheduling of return demonstrations by Nurse Mentors as compared to Clinical Instructors. The frequency of return demonstration is more or less similar by both the Nurse Mentors as well as the Clinical Instructors. Therefore, $\mathrm{H}_{2}$ accepted, $\mathrm{H}_{0}$ is rejected.
As displayed in table, at Serial No.10, the level of satisfaction of students was significantly higher on scale $(\mathrm{p}=0.001)$ regarding the motivational level to perform better in clinical setup under the guidance of Nurse Mentors as compared to Clinical Instructors. It can thus be interpreted that presence of Nurse Mentors is a better motivational factor for the students to do better in clinical set up as compared to the presence of Clinical Instructors. Therefore $\mathrm{H}_{2}$ accepted, $\mathrm{H}_{0}$ is rejected.

As displayed in table, at Serial No.11, all the respondents felt that presence of Nurse Mentors permanently for the purpose of clinical Teaching will be most appreciable. This indicates that the overall satisfaction level of the student is high for the permanent appointment of Nurse Mentors for the teaching of the students as compared to appointment of Clinical Instructors. Therefore, $\mathrm{H}_{2}$ accepted, $\mathrm{H}_{0}$ is rejected.

\section{Summary and Conclusion}

Overall the satisfaction level of the student nurses was very high related to mentors for the teaching of the students as compared to appointment of Clinical Instructors "Thus it can be interpreted that appointment of Clinical Nurse Mentors for the purpose of clinical Teaching- Learning process may be a good decision by Colleges of Nursing."

\section{Implications}

- Nursing Education: Clinical Nurse Mentors enhance the quality of nursing education by keeping the motivational level of the students high.

- Appointing Clinical Nurse Mentors is an opportunity for providing better nursing education.

- Nursing Practice: Clinical Nurse Mentors bridge the gap between nursing education and nursing practice. This dual role of a nursing professional enhances better on hands training of nursing students and provides opportunities for standardization of nursing practice. 
- Nursing Research: The concept of Appointing Clinical Nurse Mentors is a new one in Indian Scenario and many research studies can be carried out to effectively judge the change in nursing education brought by Clinical Nurse Mentors.

\section{Recommendations:}

1. Reciprocation of similar study in different set up

2. Comparative study of satisfaction levels of B.Sc. and P.B.B.Sc. Students

3. Study of Nurse Mentors' Satisfaction level

4. Effect of Nurse Mentors on Clinical Performance of Nursing Students

From the present study, it was found Mentoring facilitates practice-based learning by assigning a student to practice with a mentor who is an experienced clinician and takes particular interest in the personal and professional development of the student. Mentoring is a learning and developmental process that assists students' achievement of competencies, orientation to the clinical role, personal and professional accomplishment. Thus the investigator who is a Nurse felt that appointment of Clinical Nurse Mentors for the purpose of clinical teaching learning process may be a good decision by Colleges of Nursing so that it helps in meeting the challenges of the transitional age.

\section{Acknowledgement}

We thank all students and staff nurses who participated in this study.

\section{Author's Contributions}

All authors equally contributed in this work.

\section{Ethics}

Informed consent taken from students and staff nurses included in the study.

\section{References}

Andrews, M. and F. Chilton, 2010. Student and mentor perceptions of mentoring effectiveness. Nurse Educ. Today, 20: 555-562.

DOI: $10.1054 /$ nedt.2000.0464

Andrews, N. and D. Roberts, 2003. Supporting student nurses learning in and through clinical practice: The role of the clinical guide. Nurse Educ. Today, 23: 474-481.DOI: 10.1016/S0260-6917(03)00076-5

Chow, F. and L. Suen, 2001. Clinical staff as mentors in pre-registration undergraduate nursing education: students' perceptions of the mentors' roles and responsibilities. Nurse Educ. Today, 21: 350-358. DOI: $10.1054 /$ nedt.2001.0569

Gray, M. and L. Smith, 2000. The qualities of an effective mentor from the student nurse's perspective: Findings from a longitudinal qualitative study. J. Adv. Nurs., 32: 1542-1549. PMID: 11136424

Marilyn, J.R., L. Hicks, V. Grando, G.F. Petroski and R.W. Madsen et al., 2004. Nursing home quality, cost, staffing and staff mix. Gerontologist, 44: 24-38. DOI: 10.1093/geront/44.1.24

William, R.T., A. Stevenson and L. Brown, 2002. Shorter Oxford English Dictionary: On Historical Principles, 5th Edn., Oxford University Press, ISBN-10: 0198604572, pp: 3750.

Simpson, J.A. and E.S.C. Weiner, 1989. The Oxford English Dictionary. 1st Edn., Clarendon Press, ISBN-10: 0191958921, pp: 22000. 